\title{
Magnitude scales for cold pressor pain
}

\author{
HENDERIKUS J. STAM, WILLIAM M. PETRUSIC, and NICHOLAS P. SPANOS \\ Carleton University, Ottawa, Ontario KIS 5B6, Canada
}

\begin{abstract}
Subjects in two experiments immersed a hand and forearm in ice water (cold pressor test) for $60 \mathrm{sec}$ and gave magnitude estimates of pain every $5 \mathrm{sec}$. Forty subjects immersed an arm for three trials in Experiment 1, and 60 subjects immersed an arm for two trials in Experiment 2. Linear, power, or additive constant functions fitted the data almost equally well. Exponents of the two-constant power function differed from those of the additive constant function. Individual differences in exponents were marked, but various psychological manipulations aimed at reducing pain failed to affect the exponents. The utility of power functions to describe cold pressor pain has yet to be determined.
\end{abstract}

The immersion of a limb in ice water, the cold pressor (CP) test, was first used to experimentally increase blood pressure in studies of hypertension (Hines \& Brown, 1933). Investigators soon discovered, however, that a relationship existed between changes in blood pressure, the temperature of the immersed hand, and subjective reports of pain (Wolf \& Hardy, 1941). A unique aching pain, distinct from cold sensations, was associated with limb immersion.

Consequently, the CP test has been used to study the effects on pain of (1) hypnotically suggested analgesia (e.g., Barber \& Hahn, 1962; Evans \& Paul, 1970; Hilgard \& Hilgard, 1975; Spanos, RadtkeBodorik, Ferguson, \& Jones, 1979), (2) cognitive coping strategies (e.g., Beers \& Karoly, 1979; Blitz \& Dinnerstein, 1971; Johnson, 1974; Scott \& Barber, 1977; Scott \& Leonard, 1978; Westcott \& Horan, 1977; Worthington, 1978), (3) stress inoculation procedures (e.g., Hackett \& Horan, 1980; Turk, 1978), (4) acupuncture (e.g., Anderson, Jamieson, \& Man, 1974; Knox \& Shum, 1977), (5) preparatory information (e.g., Leventhal, Brown, Shacham, \& Engquist, 1979), (6) self-control (e.g., Berger \& Kanfer, 1975; Kanfer \& Seidner, 1973), and other phenomena of psychological interest (see Lovallo, 1975).

Despite its wide use, very few psychophysical data are available concerning CP-induced pain. Most investigators have simply relied on a threshold and/or tolerance measure of pain or the difference between these two (sometimes called the pain sensitivity range; see Wolff, 1971). One problem with these measures stems from the cyclical nature of $\mathrm{CP}$ pain. It peaks at approximately $60 \mathrm{sec}$, subsides, and then increases

This research was supported by an SSHRC Doctoral Fellowship awarded to H. J. Stam, Grant APA-0238 from the National Research Council awarded to W. M. Petrusic, and Grant PR873 from the Ontario Ministry of Health awarded to N. P. Spanos, We thank H. L. Radtke for critically reading earlier versions of this article. Requests for reprints should be sent to H. J. Stam, Department of Psychology, Carleton University, Ottawa, Ontario K1S 5B6, Canada. again at various intervals (see Kunkle, 1949; Lovallo, 1975; Wolf \& Hardy, 1941). Thus, tolerance levels beyond $60 \mathrm{sec}$ are difficult to interpret. Furthermore, individual differences appear more marked for cold pressor pain measures of tolerance than for other standard pain stimuli (Davidson \& McDougall, 1969), and category ratings of discomfort taken during $\mathrm{CP}$ testing do not always correlate significantly with CP pain tolerance measures (e.g., Avia \& Kanfer, 1980).

In order to avoid these problems, some investigators have used a category rating scale procedure instead of threshold or tolerance measures. Typically, subjects give only one report on a category scale, usually at the time they remove their arm from the water. Thus, no information is obtained about the growth rate of pain. Subjects simply give some overall impression of their pain.

The only psychophysical investigations of CP pain to date have been conducted by Hilgard and his associates. Subjects were asked to report pain every $5 \mathrm{sec}$ on a modified category scale. The scale ranged from 1 to 10 , where 10 was the value "at which the subject would very much like to remove his hand from the water," but the subject was exhorted to "endure the pain beyond this and to count beyond 10 as the pain continued to mount'" (Hilgard, Ruch, Lange, Lenox, Morgan, \& Sachs, 1974). Although Hilgard et al. refer to this procedure as "magnitude estimation" (ME), it in fact confounds category rating and ME procedures. The subject is asked to equipartition the subjective pain continuum, with the upper end of the scale left ambiguous. Thus, it is unclear whether meaningful magnitude scales can be obtained from these procedures.

We report two experiments that were designed to obtain formal characterizations of the growth of $\mathrm{CP}$ pain with time using traditional ME procedures. On the basis of these characterizations, the efficacy of hypnotically suggested analgesia was examined in two experiments. Stam and Spanos (1980) discussed the results of the first experiment as it relates to the 
efficacy of the analgesia manipulations, but they did not present the psychophysical functions obtained. The second experiment extends and replicates the first, using suggestions for analgesia, a nonimaginal distraction task, or a no-treatment control trial. In addition, since a modulus was used in the second experiment but not in the first, the two experiments taken together permitted determining the effects of using a modulus on the form of the psychophysical function (see Macmillan, Moschetto, Bialostozky, \& Engel, 1974; Poulton, 1968).

\section{METHOD}

\section{Subjects}

Twenty male and 20 female Carlton University undergraduates participated in Experiment 1, and 30 male and 30 female undergraduates participated in Experiment 2. Subjects in Experiment 1 had scored high (from 9 to 12) on the Harvard Group Scale of Hypnotic Susceptibility, Form A (HGSHS:A; Shor \& Orne, 1962), a reliable and standardized measure of hypnotic susceptibility. Subjects in Experiment 2 had scored either high (9-12) or low (0-3) on the HGSHS:A, and each susceptibility level included 15 males and 15 females. All subjects volunteered to participate in an individual session in which their arm and forearm would be immersed in ice water. They were forewarned that the experience was likely to be painful, and all were paid $\$ 3.00$ for their participation.

\begin{abstract}
Apparatus
Two plastic tanks, $25.4 \times 35.6 \times 38.1 \mathrm{~cm}$, held the ice and water used as the cold pressor stimulus. A wire mesh screen divided the containers into two equal sections, one containing crushed ice and the other ice-free water. The subject's hand and forearm were immersed into the ice-free water, which was circulated to prevent local warming. The water was maintained at a temperature between $0^{\circ} \mathrm{C}$ and $2^{\circ} \mathrm{C}$ during each immersion.
\end{abstract}

\section{Procedure}

Experiment 1. A familiarization task was used to acquaint all subjects with the general ME procedure. Each subject was asked to estimate the length of various lines by assigning a number of his or her own choosing to the first line and then judging all subsequent lines relative to the first. Upon completion, the subject was given the following instructions: "Now I am going to place your arm in the water. Every few seconds I will say report. Whenever I say report, I want you to give me a number that corresponds to the intensity of the pain you are feeling at that moment .... The first time I say report, call the pain any number that seems appropriate to you. Then assign successive numbers in such a way that they reflect your subjective impression ....."

The experimenter said "report" every 5 sec during each immersion and also recorded the subject's response. Thus, each subject gave 12 magnitude estimates during each immersion.

An equal number of males and females $(n=5)$ were assigned randomly to four treatment groups. Subjects in all groups underwent three 60 -sec ice-water immersion trials. The first (baseline) immersion trial was the same for all subjects. After being seated between the ice-water containers and taught the ME procedure, each subject had a hand and forearm (right and left were counterbalanced) immersed in the water. Every $5 \mathrm{sec}$, the subject called out a number that corresponded to his/her level of pain, and after $60 \mathrm{sec}$, the arm was withdrawn and dried. For the next immersion, the arm not used on the previous immersion was the test arm. Immersions were separated by approximately $10 \mathrm{~min}$. At this point, treatment procedures differed depending on group assignment.

Group 1 received a standardized analgesia suggestion, modified slightly from Spanos, Barber, and Lang (1974), prior to their second immersion. The suggestion asked subjects to think of their arm as numb and insensitive and to imagine it as a piece of rubber. Following their second immersion, these subjects were administered a standardized 10-min hypnotic induction procedure followed by the same analgesia suggestion administered previously. The remainder of Trials 2 and 3 was as described above. Group 2 was informed, following their baseline trial, that they would receive two more immersions and that each immersion would be preceded by an analgesia suggestion. The analgesia suggestion and the immersion procedures were as above. Group 3 was given the same hypnotic and waking analgesia treatments used for Group 1, with the exception that the order of treatments was reversed. These subjects received hypnotic analgesia for their second immersion and waking analgesia for their third. Group 4 received no treatment; their second and third immersions were the same as the baseline. Further details of these procedures may be found in Stam and Spanos (1980).

Experiment 2. Subjects in this experiment were given the same line familiarization task used in Experiment 1, with the exception that subjects were now to estimate the lengths relative to a standard line called " 100 ." Next, subjects had a hand and forearm immersed in ice water for $10 \mathrm{sec}$, with right and left arms counterbalanced. The intensity of the pain experienced at $10 \mathrm{sec}$ was labeled " 100 " and served as the standard against which all other intensities were to be judged. Subjects were then informed that they were to immerse their opposite arm and that, every few seconds following this immersion, the experimenter would say "report." Upon hearing "report," they were to call out a number proportional to the standard that reflected their level of pain (e.g., a pain twice as intense as the standard was to be called " 200 ," half as intense, " 50 ," and so on). Subjects were asked to report every $5 \mathrm{sec}$ during the immersion and thus gave 12 magnitude estimates of pain. Trial 2 procedures were identical to these in that subjects again received the standard and gave magnitude estimates as above. Immersions were approximately $10 \mathrm{~min}$ apart.

All subjects received two 60 -sec $\mathrm{CP}$ trials, the first of which served as a baseline trial. Prior to Trial 2, subjects within each susceptibility level were assigned randomly to three treatments, with the restriction that there be an equal number of males and $\mathrm{fe}-$ males $(n=5)$ per treatment. Following their second exposure to the $10 \mathrm{sec}$ standard, subjects were administered the following treatments: (1) Suggestion group subjects received the same suggestion as subjects in Experiment 1. This time, however, subjects were given the suggestion, were given $60 \mathrm{sec}$ to practice achieving the suggested effects, and were then readministered the suggestion prior to arm immersion. They then rated their pain as above. (2) Distraction group subjects were shown a Lafayette Model 2203E photoelectric rotary pursuit apparatus on which a shaft of light rotated 45 times per min. They were informed that their task would be to track the light, with the stylus held in one hand while their other hand was immersed in the ice water. Subjects were given $60 \mathrm{sec}$ of practice on this task prior to immersion. During their immersion, they rated their pain as above. (3) Control group subjects received no treatment and merely repeated their baseline immersion. Further details may be found in Spanos, Stam, and Brazil (in press).

\section{RESULTS}

\section{Treatments}

A two-constant power function (e.g., Stevens, 1975),

$$
\psi=b \phi^{a},
$$

was calculated for each subject's immersion on each trial. The resulting exponents and log constants from the functions in Experiment 1 were then each subjected to a 4 by 3 split-plot analysis of variance 
Table 1

Summary Statistics for Slopes and Intercepts Derived From Individual Log-Linearized Power Functions

\begin{tabular}{|c|c|c|c|c|c|c|c|c|c|}
\hline \multirow[b]{2}{*}{ Trial } & \multicolumn{4}{|c|}{ Slope } & \multicolumn{4}{|c|}{ Intercept } & \multirow{2}{*}{ Median $\mathbf{R}^{2}$} \\
\hline & Mean & SD & Median & Range & Mean & SD & Median & Range & \\
\hline \multicolumn{10}{|c|}{ Experiment 1} \\
\hline $\begin{array}{l}1 \\
2 \\
3\end{array}$ & $\begin{array}{l}.697 \\
.677 \\
.717\end{array}$ & $\begin{array}{l}.258 \\
.288 \\
.316\end{array}$ & $\begin{array}{l}.747 \\
.692 \\
.748\end{array}$ & $\begin{array}{l}1.01 \\
1.23 \\
1.18\end{array}$ & $\begin{array}{r}.234 \\
.150 \\
-.006\end{array}$ & $\begin{array}{l}.392 \\
.390 \\
.434\end{array}$ & $\begin{array}{r}.207 \\
.092 \\
-.035\end{array}$ & $\begin{array}{l}1.75 \\
1.60 \\
1.64\end{array}$ & $\begin{array}{l}.949 \\
.955 \\
.945\end{array}$ \\
\hline \multicolumn{10}{|c|}{ Experiment 2} \\
\hline $\begin{array}{l}1 \\
2\end{array}$ & $\begin{array}{l}.629 \\
.623\end{array}$ & $\begin{array}{l}.304 \\
.313\end{array}$ & $\begin{array}{l}.601 \\
.622\end{array}$ & $\begin{array}{l}1.36 \\
1.31\end{array}$ & $\begin{array}{l}1.370 \\
1.310\end{array}$ & $\begin{array}{l}.402 \\
.430\end{array}$ & $\begin{array}{l}1.380 \\
1.350\end{array}$ & $\begin{array}{l}1.93 \\
1.72\end{array}$ & $\begin{array}{l}.935 \\
.935\end{array}$ \\
\hline
\end{tabular}

(ANOVA) with one between-subjects variable (4 groups) and one within-subjects variable (3 immersions). ${ }^{1}$ Neither main effects nor interactions with slopes as the dependent measure achieved statistical significance. The ANOVA on the log constants revealed a statistically significant main effect for the immersions factor $[F(2,72)=14.61, p<.01]$. NewmanKeuls post hoc comparisons $(\mathrm{p}<.05)$ indicated that the log constants were significantly lower on Immersion 3 than on either Immersion 1 or Immersion 2, while the latter two did not differ. The Group by Trials interaction did not approach statistical significance.

The exponents and log constants derived from Experiment 2 were each subjected to a 2 by 3 by 2 splitplot ANOVA with two between-subjects variables (high/low susceptibility by 3 groups) and one withinsubjects variable ( 2 trials). Neither main effects nor interactions in either of the ANOVAs approached significance, precluding discussion of group differences.

The mean, SD, median, and range for the exponents and $\log$ constants on the three immersion trials in Experiment 1 and the two immersion trials in Experiment 2 are presented in Table 1 along with the median coefficients of determination.

\section{Fitted Functions}

In each experiment, geometric means were calculated for each duration interval during each trial.
These were fitted to three functions and tested for goodness of fit: (1) the two-constant power function (Equation 1); (2) a linear function,

$$
\psi=\mathbf{a} \phi+\mathbf{b}
$$

and (3) an additive constant power function,

$$
\psi=b \phi^{a}+c .
$$

All three were fitted by the method of least squares. For Equation 3, Marquardt's (1963) algorithm for the least squares estimation of nonlinear parameters was used. This algorithn, also known as the maximum neighborhood method, performs an optimum interpolation between the Taylor series method and the gradient (or steepest descent) method based upon the maximum neighborhood in which the truncated Taylor series provides an adequate representation of the model.

Equation 3 was also fitted by maximizing the coefficient of determination between $\log (\psi-c)$ and $\log (\phi)$ using a simple iterative computer program. Once a value of $c$ was determined, the values of a and b were found by conventional least squares. This procedure of fitting the additive constant power function follows that of Parker, Schneider, and Kanow (1975) and Petrusic and Jamieson (1979).

Tables 2 and 3 present the parameters and coefficients of determination for the functions, calculated

Table 2

\begin{tabular}{|c|c|c|c|c|c|c|c|c|}
\hline \multirow[b]{3}{*}{ Trial } & \multicolumn{4}{|c|}{$\Psi=a \phi+b$} & \multicolumn{4}{|c|}{$\Psi=\mathrm{b} \phi^{\mathrm{a}}$} \\
\hline & \multicolumn{2}{|c|}{ a } & \multirow[b]{2}{*}{ b } & \multirow[b]{2}{*}{$\mathrm{R}^{2}$} & \multicolumn{2}{|c|}{$\mathbf{a}$} & \multirow[b]{2}{*}{ b } & \multirow[b]{2}{*}{$\mathrm{R}^{2}$} \\
\hline & Mean & SE & & & Mean & SE & & \\
\hline \multicolumn{9}{|c|}{ Experiment 1} \\
\hline $\begin{array}{l}1 \\
2 \\
3\end{array}$ & $\begin{array}{l}.457 \\
.338 \\
.284\end{array}$ & $\begin{array}{l}.0076 \\
.0070 \\
.0078\end{array}$ & $\begin{array}{l}3.95 \\
3.43 \\
2.41\end{array}$ & $\begin{array}{r}.9973 \\
.9957 \\
.9925\end{array}$ & $\begin{array}{l}.697 \\
.677 \\
.717\end{array}$ & $\begin{array}{l}.018 \\
.012 \\
.023\end{array}$ & $\begin{array}{r}1.71 \\
1.41 \\
.99\end{array}$ & $\begin{array}{l}9932 \\
.9969 \\
.9895\end{array}$ \\
\hline \multicolumn{9}{|c|}{ Experiment 2} \\
\hline $\begin{array}{l}1 \\
2\end{array}$ & $\begin{array}{l}4.452 \\
3.665\end{array}$ & $\begin{array}{l}.1080 \\
.1390\end{array}$ & $\begin{array}{l}55.10 \\
51.30\end{array}$ & $\begin{array}{l}.9941 \\
.9858\end{array}$ & $\begin{array}{l}.629 \\
.623\end{array}$ & $\begin{array}{l}.019 \\
.012\end{array}$ & $\begin{array}{l}23.40 \\
20.40\end{array}$ & $\begin{array}{l}.9913 \\
.9963\end{array}$ \\
\hline
\end{tabular}

Fitted Parameters for the Linear and Power Functions 
Table 3

Fitted Parameters for the Additive Constant Function

\begin{tabular}{|c|c|c|c|c|c|c|c|c|c|c|}
\hline \multirow[b]{3}{*}{ Trial } & \multicolumn{5}{|c|}{$\Psi=\mathrm{b} \phi^{\mathrm{a}}+\mathrm{c}\left(\right.$ Maximizing $\left.\mathrm{R}^{2}\right)$} & \multicolumn{5}{|c|}{$\Psi=b \phi^{a}+c($ Marquardt $)$} \\
\hline & \multicolumn{2}{|c|}{ a } & \multirow[b]{2}{*}{ b } & \multirow[b]{2}{*}{$\mathrm{c}$} & \multirow[b]{2}{*}{$\mathrm{R}^{2}$} & \multicolumn{2}{|c|}{ a } & \multirow[b]{2}{*}{$\mathrm{b}$} & \multirow[b]{2}{*}{ c } & \multirow[b]{2}{*}{$\mathrm{R}^{2}$} \\
\hline & Mean & SE & & & & Mean & SE & & & \\
\hline \multicolumn{11}{|c|}{ Experiment 1} \\
\hline $\begin{array}{l}1 \\
2 \\
3\end{array}$ & $\begin{array}{l}.925 \\
.795 \\
.953\end{array}$ & $\begin{array}{l}.0065 \\
.0083 \\
.0236\end{array}$ & $\begin{array}{l}.643 \\
.839 \\
.360\end{array}$ & $\begin{array}{l}2.91 \\
1.38 \\
1.77\end{array}$ & $\begin{array}{l}.9995 \\
.9989 \\
.9939\end{array}$ & $\begin{array}{l}.857 \\
.811 \\
.766\end{array}$ & $\begin{array}{l}.035 \\
.039 \\
.054\end{array}$ & $\begin{array}{l}.862 \\
.785 \\
.809\end{array}$ & $\begin{array}{r}2.116 \\
1.532 \\
.319\end{array}$ & $\begin{array}{l}.9990 \\
.9988 \\
.9975\end{array}$ \\
\hline \multicolumn{11}{|c|}{ Experiment 2} \\
\hline $\begin{array}{l}1 \\
2\end{array}$ & $\begin{array}{l}.888 \\
.757\end{array}$ & $\begin{array}{l}.0113 \\
.0095\end{array}$ & $\begin{array}{r}7.440 \\
11.100\end{array}$ & $\begin{array}{l}38.82 \\
20.44\end{array}$ & $\begin{array}{l}.9984 \\
.9984\end{array}$ & $\begin{array}{l}.779 \\
.652\end{array}$ & $\begin{array}{l}.043 \\
.054\end{array}$ & $\begin{array}{l}11.950 \\
17.910\end{array}$ & $\begin{array}{r}24.680 \\
3.790\end{array}$ & $\begin{array}{l}.9985 \\
.9973\end{array}$ \\
\hline
\end{tabular}

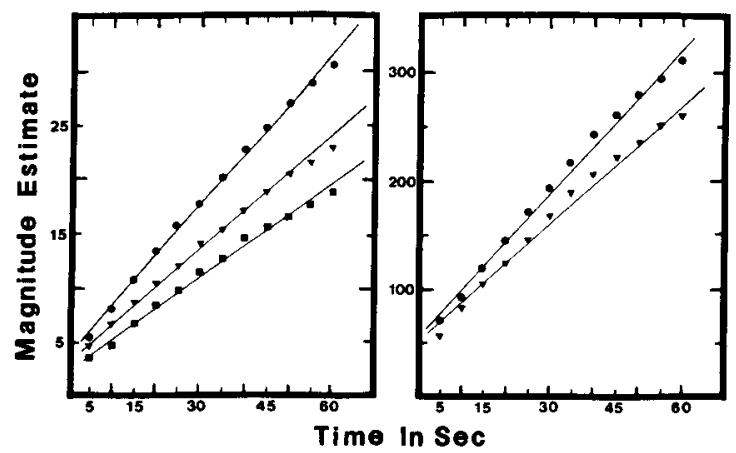

Figure 1. Litear functions for Experiment 1 (left) and Experiment 2 (right). Circles, triangles, and squares represent Trials 1 , 2 , and 3 , respectively.
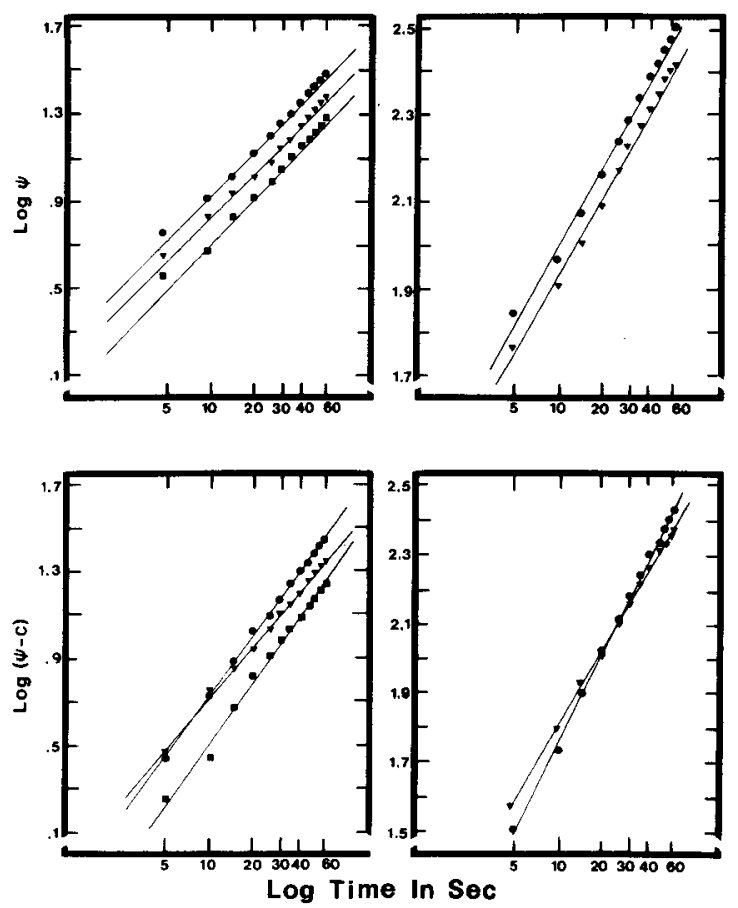

Figure 2. Power functions (upper panels) and additive constant functions-maximizing $R^{2}$ (lower panels) for Experiment 1 (left) and Experiment 2 (right). Circles, triangles, and squares represent Trials 1, 2, and 3, respectively. separately for each trial in Experiments 1 and 2. All functions are plotted in Figures 1, 2, and 3, separately for each experiment.

\section{DISCUSSION}

\section{Treatments}

The data in Table 1 show that the exponents derived from the individual power functions are extremely variable even on the baseline trials prior to experimental manipulations. These results are consistent with those of other researchers (e.g., Baird \& Noma, 1978) who have found individual exponents to be nearly normally distributed. To what extent these differences are a function of judgmental rather than sensory differences is impossible to determine from these results. Subjects may confuse affective and sensory "components" of pain when they are asked to describe the "intensity of the pain." Although investigators typically avoid this issue by describing subjects' ratings as "reported pain," recent attempts have been made to untangle these variables theoretically and empirically (e.g., Goldberger \& Tursky, 1976; Gracely, McGrath, \& Dubner, 1978; Rollman, 1977). Clearly, further investigation is needed to determine how these variables affect magnitude estimates of pain.

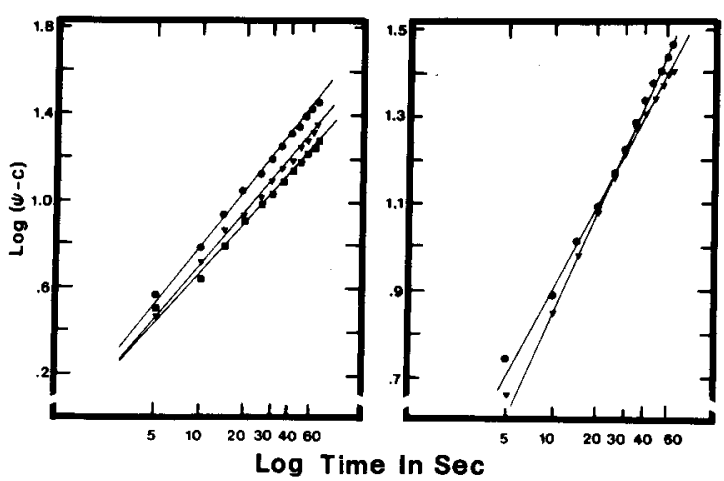

Figure 3. Additive constant functions-Marquardt's algorithm for Experiment 1 (left) and Experiment 2 (right). Circles, triangles, and squares represent $T$ rials 1,2 , and 3 , respectively. 
Our findings indicate that the psychological manipulations exerted no effect on the exponents of the two-constant power function (Equation 1). The constants in Experiment 1 were significantly lower on Immersion 3 than on Immersions 1 and 2. Neither exponents nor constants, however, were changed by our manipulations in Experiment 2. This trial effect difference in the two experiments may have been artifactual, perhaps due to the use of a standard in Experiment 2 but not in Experiment 1. The use of a modulus of " 100 " resulted in magnitude estimates that were considerably larger than those obtained in Experiment 1, in which subjects responded freely. Accordingly, upon logarithmically transforming the magnitude estimates, differences among constants over trials were necessarily larger in the first experiment, and, consequently, the possibility of obtaining trial differences in constants was reduced in the second experiment.

The fact that subjects usually reported lower magnitude estimates in suggestion than in nonsuggestion treatments was confirmed by treating their estimates as scores in a factorial design and conducting analyses of variance. These results, reported in Spanos et al. (in press) and in Stam and Spanos (1980), confirmed the efficacy of the manipulations. It may be that, for CP pain, the computation of a separate exponent for each subject results in individual differences that are great enough to mask treatment effects. This is, of course, speculative and could be subjected to further testing.

\section{Best-Fitting Function}

The linear and power functions appear to provide equally good fits (minimum $\mathbf{R}^{2}=.9858$ ). The additive constant functions, accounting for over $99.4 \%$ of the variance, provide the best fit. The superiority of Equation 3, however, is found mostly at the third decimal place and is gained at the expense of adding a parameter to the model. Furthermore, relative to Equation 1, the exponents of Equation 3 are greater, on the average, by .1 (Marquardt's algorithm) and .2 (maximizing $\mathrm{R}^{2}$ ). That the exponent depends not only on the form of the function, but also on the algorithm used to calculate it, makes the search for a characteristic exponent of $\mathrm{CP}$ pain somewhat arbitrary. More important, however, these results imply that investigators using different procedures to estimate parameters of nonlinear functions could conceivably obtain different results depending on their choice of algorithm.

The good fits obtained with all the functions may be due in part to the confounding of duration with intensity. Also, discrimination between levels of stimulus intensity is probably enhanced when the intensities are presented in a single, ascending order. This problem is unique to $C P$ pain and could be re- duced in part by having subjects rate a large number of immersions of differing durations.

The use of an additive constant to correct for curvature or the origin of the response scale has been the subject of some debate (e.g., Dawson \& Miller, 1978a, 1978b; Marks, 1978; Marks \& Cain, 1972; McCallum \& Goldberg, 1974; Rule \& Curtis, 1973). Typically, translations on the response scale have been proposed as more satisfactory than translations on the stimulus scale (e.g., Fagot \& Stewart, 1968; Irwin \& Corballis, 1968; McGill, 1960; Ross \& DiLollo, 1971). In the present case, however, in which data are relatively linear, the meaning of such an addition remains unclear. The use of power functions to describe CP pain may be premature. Linearity, on the other hand, appears to characterize the growth of cold pressor pain simply and elegantly.

\section{REFERENCES}

Anderson, D. G., Jamieson, J. L., \& Man, S. C. Analgesic effects of acupuncture on the pain of ice-water: A double-blind study. Canadian Journal of Psychology, 1974, 28, 239-244.

Avia, M. D., \& Kanfer, F. H. Coping with aversive stimulation: The effects of training in a self-management context. Cognitive Therapy and Research, 1980, 4, 73-81.

BAIRD, J. C., \& Noma, E. Fundomentals of scaling and psychophysics. New York: Wiley, 1978.

Barber, T. X., \& HAHN, K. W., Jr. Physiological and subjective responses to pain producing stimulation under hypnoticallysuggested and waking-imagined "analgesia." Journal of $A b$ normal and Social Psychology, 1962, 65, 411-418.

BeErs, T. M., JR., \& KARoLY, P. Cognitive strategies, expectancy, and coping style in the control of pain. Journal of Consulting and Clinical Psychology, 1979, 47, 179-180.

Berger, S., \& Kanfer, F. H. Self-control: Effects of training and presentation delays of competing responses on tolerance of noxious stimulation. Psychological Reports, 1975, 37, 1312-1314.

Blitz, B., \& Dinnerstein, A. J. Role of attentional focus in pain perception: Manipulation of response to noxious stimulation by instructions. Journal of Abnormal Psychology, 1971, 77, $42-45$.

Davidson, P. O., \& McDougall, C. E. A. The generality of pain tolerance. Journal of Psychosomatic Research, 1969, 13, 83-89.

Dawson, W. E., \& Mrller, M. E. Inverse attribute functions and the proposed modifications of the power law. Perception \& Psychophysics, 1978, 24, 457-465. (a)

Dawson, W. E., \& Miller, M. E. A reply to the critique of Marks. Perception \& Psychophysics, 1978, 24, 571. (b)

Evans, M. B., \& Paul, G. L. Effects of hypnotically suggested analgesia on physiological and subjective response to cold stress. Journal of Consulting and Clinical Psychology, 1970, 35, 362-371.

Fagot, R. F., \& Stewart, M. R. An experimental comparison of stimulus and response translated power functions for brightness. Perception \& Psychophysics, 1968, 3, 297-305.

Goldberger, S. M., \& TuRSky, B. Modulation of shock-elicited pain by acupuncture and suggestion. Pain, 1976, 2, 417-429.

Gracely, R. H., McGrath, P., \& Dubner, R. Ratio scales of sensory and affective verbal pain descriptors. Pain, 1978, 5, 5-18.

HACKETT, G., \& Horan, J. J. Stress-inoculation for pain: What's really going on? Journal of Counseling Psychology, 1980, 27, 107-116.

Hilgard, E. R., \& Hilgard, J. R. Hypnosis in the relief of pain. Los Altos, Calif: Kaufmann, 1975. 
Hilgard, E. R., Ruch, J. C., Lange, A. F., Lenox, J. R., Morgan, A. H., \& Sachs, L. B. The psychophysics of cold pressor pain and its modification through hypnotic suggestion. American Journal of Psychology, 1974, 87, 17-31.

Hines, E. A., JR., \& Brown, G. E. A standard test for measuring the variability of blood pressure: Its significance as an index of the prehypertensive state. Annals of Internal Medicine, 1933, 7, 209-217.

Irwin, R. J., \& Corballis, M. C. On the general form of Stevens' law for loudness and softness. Perception \& Psychophysics, $1968,3,137-143$.

Johnson, R. F. Q. Suggestions for pain reduction and response to cold-induced pain. Psychological Record, 1974, 24, 138-156.

KANFEr, F. H., \& SEIDNER, M. L. Self-control: Factors enhancing tolerance of noxious stimulation. Journal of Personality and Social Psychology, 1973, 25, 381-389.

Knox, V. J., \& Shum, K. Reduction of cold pressor pain with acupuncture and analgesia in high and low hypnotic subjects. Journal of Abnormal Psychology, 1977, 86, 639-643.

KunkLE, E. C. Phasic pains induced by cold. Journal of Applied Physiology, 1949, 1, 811-824.

Leventhal, H., Brown, D., Shacham, S., \& Engquist, G. Effects of preparatory information about sensations, threat of pain, and attention on cold pressor distress. Journal of Personality and Social Psychology, 1979, 37, 688-714.

Lovallo, W. The cold pressor test and autonomic function: A review and integration. Psychophysiology, 1975, 12, 268-282.

Macmillan, N. A., Moschetto, C. F., Bialostozky, F. M., \& ENGEL, L. Size judgment: The presence of a standard increases the exponent of the power law. Perception \& Psychophysics, 1974, 16, 340-346.

Marks, L. E. A critique of Dawson and Miller's "Inverse attribute functions and the proposed modifications of the power law." Perception \& Psychophysics, 1978, 24, 569-570.

Marks, L. E., \& CAIN, W. S. Perception of intervals and magnitudes for three prothetic continua. Journal of Experimental Psychology, 1972, 94, 6-17.

MARquARDT, D. W. An algorithm for least-squares estimation of nonlinear parameters. Journal of the Society for Industrial and Applied Mathematics, 1963, 11, 431-441.

McCallum, P., \& Goldberg, H. Magnitude scales for electrocutaneous stimulation. Perception \& Psychophysics, 1974, 17, 75-78.

McGill, W. A. The slope of the loudness function: A puzzle. In H. Gulliksen \& S. Messick (Eds.), Psychological scaling: Theory and application. New York: Wiley, 1960.

Parker, S., Schneider, B., \& Kanow, G. Ratio scale measurement of the perceived lengths of lines. Journal of Experimental Psychology: Human Perception and Performance, 1975, 104, 195-204.

Petrusic, W. M., \& Jamieson, D. G. Resolution time and the coding of arithmetic relations on supraliminally different visual extents. Journal of Mathematical Psychology, 1979, 19, 89-107.

Poulton, E. C. The new psychophysics: Six models for magnitude estimation. Psychological Bulletin, 1968, 69, 1-19.

Rollman, G. B. Signal detection theory measurement of pain: A review and critique. Pain, 1977, 3, 187-211.
Ross, J., \& DiLollo, V. Judgment and response in magnitude estimation. Psychological Review, 1971, 78, 515-527.

Rule, S. J., \& Curtis, D. W. Reevaluation of two models for judgments of perceptual intervals. Perception \& Psychophysics, $1973,14,433-436$.

SCOTT, D. S., \& BARBer, T. X. Cognitive control of pain: Effects of multiple cognitive strategies. Psychological Record, 1977, 27, 373-383.

ScotT, D. S., \& Leonard, C. F., JR. Modification of pain threshold by the covert reinforcement procedure and a cognitive strategy. Psychological Record, 1978, 28, 49-57.

Shor, R. E., \& Orne, E. C. Harvard Group Scale of Hypnotic Susceptibility, Form A. Palo Alto, Calif: Consulting Psychologists Press, 1962.

Spanos, N. P., Barber, T. X., \& Lang, G. Cognition and selfcontrol: Cognitive control of painful sensory input. In $\mathrm{H}$. London \& R. E. Nisbett (Eds.), Thought and feeling: Cognitive alteration of feeling states. Chicago: Aldine, 1974.

Spanos, N. P., Radtke-Bodorik, H. L., Ferguson, J. D., \& Jones, B. The effects of hypnotic susceptibility, suggestions for analgesia, and the utilization of cognitive strategies on the reduction of pain. Journal of Abnormal Psychology, 1979, 88, 282-292.

Spanos, N. P., Stam, H. J., \& Brazil, K. The effects of suggestion and distraction on coping ideation and reported pain. Journal of Mental Imagery, in press.

Stam, H. J., \& Spanos, N. P. Experimental designs, expectancy effects, and hypnotic analgesia. Journal of Abnormal Psychology, 1980, 89, 751-762.

Stevens, S. S. Psychophysics. New York: Wiley, 1975.

Turk, D. C. Cognitive behavioral techniques in the management of pain. In J. P. Foreyt \& D. P. Rathjen (Eds.), Cognitive behavior therapy: Research and application. New York: Plenum, 1978.

WEstcotT, T. B., \& Horan, J. J. The effects of anger and relaxation forms of in vivo emotive imagery on pain tolerance. Canadian Journal of Behavioural Science, 1977, 9, 216-223.

Wolf, S., \& HARDY, J. D. Studies on pain. Observations on pain due to local cooling and on factors involved in the "cold pressor" effect. Journal of Clinical Investigation, 1941, 20, 512-533.

WolfF, B. B. Factor analysis of human pain responses: Pain endurance as a specific pain factor. Journal of Abnormal Psy. chology, 1971, 78, 292-298.

Worthington, E. L., JR. The effects of imagery content, choice of imagery content, and self-verbalization on the self-control of pain. Cognitive Therapy and Research, 1978, 2, 225-240.

\section{NOTE}

1. The constants (b) were positively skewed in both experiments. Consequently, log constants were used in all analyses of individually determined power functions.

(Received for publication September 2, 1980; revision accepted March 25, 1981.) 